\title{
Activation of Microglia in Specific Hypothalamic Nuclei and the Cerebellum of Adult Rats Exposed to Neonatal Overnutrition
}

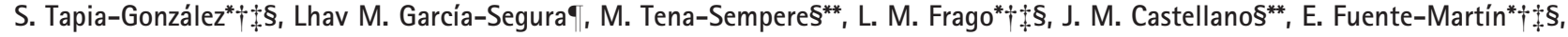 \\ C. García-Cáceres* $† \$ \S$, J. Argente ${ }^{*} \dagger \$$ and J. A. Chowen* $\$ \S$ \\ *Department of Endocrinology, Hospital Infantil Universitario Niño Jesús, Spain. \\ $\dagger$ Department of Pediatrics, University Aútonoma of Madrid, Madrid, Spain. \\ $\$$ Instituto de Investigación Sanitaria La Princesa, Spain. \\ §CIBER de Fisiopatología de Obesidad y Nutrición, Instituto de Salud Carlos III, Spain. \\ -Instituto Cajal, CSIC, Spain. \\ ${ }^{*}$ Department of Cell Biology, Physiology and Immunology, Instituto de Investigaciónes Biomédicas de Córdoba (IMIBIC), University of Córdoba, Córdoba, Spain.
}

\section{Journal of Neuroendocrinology}

Correspondence to:

Dr Julie A. Chowen, Department of Endocrinology, Hospital Infantil Universitario Niño Jesús, Avenida Menéndez Pelayo 65, 28009 Madrid, Spain (e-mail: jachowen@ telefonica.net).
Much attention has been drawn to the possible involvement of hypothalamic inflammation in the pathogenesis of metabolic disorders, especially in response to a high-fat diet. Microglia, the macrophages of the central nervous system, can be activated by proinflammatory signals resulting in the local production of specific interleukins and cytokines, which in turn could exacerbate the pathogenic process. Because obesity itself is considered to be a state of chronic inflammation, we evaluated whether being overweight results in microglial activation in the hypothalamus of rats on a normal diet. Accordingly, we used a model of neonatal overnutrition that entailed adjustment of litter size at birth (small litters: four pups/dam versus normal litters: 12 pups/dam) and resulted in a 15\% increase in bodyweight and increased circulating leptin levels at postnatal day 60. Rats that were overnourished during neonatal life had an increased number of activated microglia in specific hypothalamic areas such as the ventromedial hypothalamus, which is an important site for metabolic control. However, this effect was not confined to the hypothalamus because significant microglial activation was also observed in the cerebellar white matter. There was no change in circulating tumour necrosis factor (TNF) $\alpha$ levels or TNF $\alpha$ mRNA levels in either the hypothalamus or cerebellum. Interleukin (IL)6 protein levels were higher in both the hypothalamus and cerebellum, with no change in IL6 mRNA levels. Because circulating IL6 levels were elevated, this rise in central IL6 could be a result of increased uptake. Thus, activation of microglia occurs in adult rats exposed to neonatal overnutrition and a moderate increase in weight gain on a normal diet, possibly representing a secondary response to systemic inflammation. Moreover, this activation could result in local changes in specific hypothalamic nuclei that in turn further deregulate metabolic homeostasis.

Key words: Obesity, IL6, TNF $\alpha$, leptin, inflammation.

doi: 10.1111/j.1365-2826.2011.02113.x

Obesity is associated with a state of chronic inflammation resulting in alterations in circulating levels of interleukins, cytokines and adipokines, largely as a result of increased production by adipose tissue, liver and cells of the immune system, which is considered to be involved in the development of many of the comorbidities associated with obesity $(1,2)$. Moreover, proinflammatory cytokines are also produced in the hypothalamus and this process of hypothalamic inflammation is proposed to participate in the induction of excess weight gain, possibly through participation in the development of central insulin/leptin resistance (3-7). Indeed, a high-fat diet induces hypothalamic inflammation and production of cytokines, including tumour necrosis factor (TNF) $\alpha$ and interleukin (IL) $1 \beta$ and 6 (3-5,8), all of which have been shown to affect metabolism (9-12). Furthermore, the increased weight gain and leptin resistance resulting from hypothalamic inflammation is suggested to involve activation of the $\mid \kappa \mathrm{B}$ kinase $\operatorname{IKK}(\beta) /$ nuclear factor 
(NF) $-\kappa$ B intracellular signalling pathway $(3,13)$ and, recently, Oh-l et al. (6) demonstrated that hypothalamic activation of this pathway induces the expression of proinflammatory cytokines during increased fat intake, exacerbating weight gain.

Microglia, the macrophages of the central nervous system (14), express major histocompatibility complex (MHC)-II and other markers when activated and produce cytokines and interleukins $(15,16)$, thus altering the local microenvironment. Indeed, these glial cells have been shown to be activated in the hypothalamus of offspring of macaques fed a high-fat diet (8), as well as by an increase in fatty acids (5). Moreover, microglia are activated by diverse proinflammatory factors or cytokines, including metabolic hormones such as leptin, which stimulate their production of IL1 $\beta$, TNF $\alpha$ and IL6 (17-19) with activation of the IKK $\beta / \mathrm{NF}-\kappa \mathrm{B}$ pathway possibly being involved in this process $(18,20)$. Hence, these glial cells could be involved in the aggravation of metabolic deregulation caused by hypothalamic inflammation, with microglial activation being the result of systemic inflammation and/or dietary signals. However, very little is known about the activation of these glial cells in response to the increased intake of a normal diet and whether this occurs early in the process of weight gain. We hypothesised that activation of microglia also occurs in response to increased bodyweight that is not associated with a high-fat diet and that this process may be detectable even with a small increase in bodyweight.

\section{Materials and methods}

All studies were approved by the local ethics committee and complied with the Royal Decree 1201/2005 (BOE number 252) pertaining to the protection of experimental animals and with the European Communities Council Directive $(86 / 609 / \mathrm{EEC})$.

\section{Adjustment of litter size}

On the day of birth, litters of Wistar rats were adjusted to six males and six females per dam ( $L 12$, control) or two males and two females ( $L 4$, overnourished), with only male rats being used for the present studies. Rats from three different litters of each litter size were used in each analysis ( $n=6$ per group). Rats were weaned on postnatal day (PND) 21 and placed four per cage with free access to rat chow and tap water. On PND 60, six rats per group were perfused through the heart with $0.1 \mathrm{~m}$ phosphate buffer (PB; pH 7.4) and then with PB-buffered $4 \%$ paraformaldehyde $(\mathrm{pH}$ 7.4) under pentobarbital anaesthesia $(1 \mathrm{mg} / \mathrm{kg})$. The brains were removed and post-fixed in the same fixative overnight at $4{ }^{\circ} \mathrm{C}$, rinsed with $\mathrm{PB}$ and stored in cryoprotection solution $(30 \%$ sucrose, $30 \%$ ethylene glycol, in PB) at $-20{ }^{\circ} \mathrm{C}$ until processed. Another group of rats ( $n=6$ per group) were sacrificed by decapitation and the brains rapidly removed and frozen on dry ice. Trunk blood was collected, the serum separated and stored at $-80{ }^{\circ} \mathrm{C}$ until processed.

\section{Leptin, TNF $\alpha$ and IL6 enzyme-linked immunosorbent assays (ELISAs)}

Serum leptin, TNF $\alpha$ and IL6 levels were measured by ELISA in accordance with the manufacturer's instructions (Linco Research Inc., St Charles MO, USA; HyCult Biotechnology bv, Uden, the Netherlands; and Cusabio, Wuhan, China, respectively) and read at 450 and $590 \mathrm{~nm}$ on an automatic plate reader (Infinite M200; Tecan, Grödig, Austria). Samples were run in duplicate in a single assay for each peptide. For leptin, the assay sensitivity was $0.04 \mathrm{ng} / \mathrm{ml}$ and the intra-assay variation was $2.2 \%$. The assay sensitivity for TNF $\alpha$ was $10 \mathrm{pg} / \mathrm{ml}$ and the intra-assay variability was $5.4 \%$. For IL6, the detection limit was $0.078 \mathrm{pg} / \mathrm{ml}$ and the intra-assay variation was $4.8 \%$.

\section{Serum lipid levels}

Triglycerides and total lipids were measured by using commercial kits purchased from SpinReact (Sant Esteve de Bas, Gerona, Spain). Plasma samples were diluted $1: 1$ and the assays performed in accordance with the manufacturer's instructions.

\section{Immunohistochemistry}

Immunohistochemistry and quantitative analysis for MHC-II was performed as described previously (21) on coronal brain sections $(50 \mu \mathrm{m})$ throughout the hypothalamus. Sagittal sections of the cerebellum, a brain area with physiological functions distinct from those of the hypothalamus, were also processed to determine whether microglia activation was anatomically specific. Tissue sections were fixed for $20 \mathrm{~min}$ at room temperature in $4 \%$ paraformaldehyde in $0.1 \mathrm{~m}$ phosphate buffer ( $\mathrm{PB}, \mathrm{pH} 7.4)$, washed in $\mathrm{PB}$ and incubated in 30\% methanol containing 3\% hydrogen peroxide for $30 \mathrm{~min}$. The sections were washed in PB with $0.3 \%$ bovine serum albumin and $0.3 \%$ Triton X-100 (wash buffer) and then incubated overnight at $4{ }^{\circ} \mathrm{C}$ in a humid chamber with anti-MHC-II (dilution 1:300; Serotec, Oxford, UK) diluted in PB containing 0.3\% Triton X-100 and 3\% normal goat serum. Sections were then washed twice in buffer and incubated for $2 \mathrm{~h}$ with horseradish peroxidase conjugated goat anti-mouse immunoglobulin $G$ (dilution 1:300; Pierce, Rockford, IL, USA). After washing, the sections were incubated in avidin-biotin peroxidase complex (ABC; Pierce) diluted $1: 500$. Peroxidase activity was revealed with $0.01 \%$ hydrogen peroxide, using 3,3'-diaminobenzidine (0.03\%; Sigma, St Louis. MO, USA). Immunostaining was absent when the primary antibody was omitted. The experimental groups were assayed in parallel.

Sections were visualised with a Zeiss Axioplan microscope (Oberkochen, Germany) and a $\times 40$ objective. Images were captured with a digital camera and processed using Image-Pro Plus software (version 5.0, Media Cybernetics Inc, Silver Spring, MD, USA). The total number of MHC-II immunopositive cellular profiles in each hypothalamic area was counted in six sections per rat and, in the cerebellar white matter, in nine sections per rat $(n=6)$.

\section{Western blotting}

The hypothalami and cerebellum were homogenised in radioimmunoprecipitation assay lysis buffer and western blotting performed as described previously (22). All primary antibodies [IL6 (PreProTech, Rocky Hill, NJ, USA); F4/80 (Santa Cruz, Santa Cruz, CA, USA); phosphorylated I $\kappa \beta$ (Cell Signaling, Danvers, MA, USA)] were used at a dilution of $1: 1000$ and incubated overnight at $4{ }^{\circ} \mathrm{C}$ under agitation. The membranes were incubated with the corresponding secondary antibody conjugated with peroxidase (Pierce), visualised by chemiluminiscence (Perkin Elmer, Boston, MA, USA) and quantified by densitometry with a Gel Logic 1500 Image analysis system (Kodak, Rochester, New York, NY, USA). Results were normalised to glyceraldehyde3-phosphate dehydrogenase (GAPDH) levels in each lane and then normalised to control levels in each assay.

\section{Quantitative real-time polymerase chain reaction (PCR)}

Total RNA was extracted from the hypothalamus and cerebellum using the Tri-Reagent (Invitrogen, Carlsbad, CA, USA) protocol. Real-time PCR to quan- 
tify IL6 and TNF $\alpha$ mRNA levels was performed as described previously (23) using assay-on-demand kits (Rn01410330 and Rn01525859, respectively; Applied Biosystems, Foster City, CA, USA) and TaqMan Universal PCR Master Mix (Applied Biosystems) in accordance with the manufacturer's directions in an ABI PRISM 7000 Sequence Detection System (Applied Biosystems). Values were normalised to the housekeeping gene GAPDH (Rn99999916). In accordance with the manufacturer's instructions, the $\Delta \Delta \mathrm{CT}$ method was used to determine relative expression levels. Statistics were performed using $\Delta \Delta \mathrm{CT}$ values.

\section{Statistical analysis}

Differences between experimental groups were analysed by unpaired Student's t-tests. Data are presented as the mean \pm SEM. $P<0.05$ was considered statistically significant.

\section{Results}

At PND 60, rats from litters of four pups weighed more than those from litters of 12 (control: $250 \pm 4.7 \mathrm{~g}$, overnourished: $289 \pm 6.9$; $P<0.01$ ) and had increased serum leptin (control: $2.8 \pm$ $0.6 \mathrm{ng} / \mathrm{ml}$, overnourished: $4.6 \pm 0.5 \mathrm{ng} / \mathrm{ml} ; \mathrm{P}<0.05)$ and IL6 levels (control: $7.9 \pm 2.7 \mathrm{pg} / \mathrm{ml}$, overnourished: $16.8 \pm 1.2 \mathrm{pg} / \mathrm{ml}$; $P<0.01)$. In both experimental groups, serum TNF $\alpha$ levels were below the level of detection of the assay in the majority of the samples (data not shown). There was no change in total lipid (control: $329.5 \pm 18.7$, overnourished: $283.1 \pm 16.3 \mathrm{mg} / \mathrm{dl}$ ) or triglyceride (control: $94.1 \pm 14.1$, overnourished: $104.5 \pm 8.2 \mathrm{mg} / \mathrm{dl}$ ) levels.

IL6 protein levels increased in both the hypothalamus and cerebellum in males from small litters (Fig. 1A,B; $P<0.01$ for both). However, no change in IL6 mRNA levels was found in either the hypothalamus (control: $100 \pm 7.7$, overnourished: $93.1 \pm 5.0 \%$ control) or cerebellum (control: $100 \pm 20.1$, overnourished: $114.3 \pm 18.7 \%$ control). Similarly, TNF $\alpha$ mRNA levels were not modified in the hypothalamus (control: $100 \pm 14.0$, overnourished: $122.8 \pm 4.2$ ) or cerebellum (control: $100 \pm 8.4$, overnourished: $114.3 \pm 18.7 \%$ control).

Phosphorylated $\mid \kappa \beta$ levels were not affected by early overnutrition/increased adult weight in either brain area (Fig. $1 C, D)$ and F4/80 was undetectable in the hypothalamus and cerebellum by western blotting. However, activated microglia could be detected by immunohistochemistry in both areas. Few MHC-II immunopositive cells were detected in the hypothalamus of control rats (Fig. 2A,C), indicating that there are few activated microglia in this brain area in normal rats, although, visually, more cells were found in overnourished rats (Fig. 2B,D). Quantitative analysis indicated a significant increase in the number of MHC-II positive cellular profiles in the grey matter of the hypothalamus of overnourished rats (Fig. 2E; $P<0.05)$. These cells appeared in the paraventricular, ventromedial (VMN), dorsomedial and arcuate nuclei, as well as in the optic chiasm (OC) and median eminence (ME). The number of MHC-II positive cellular profiles was significantly increased in the VMN, OC and ME of overnourished rats (Table 1). The density of MHC-II immunopositive cells was also increased in the cerebellum of overnourished rats (Fig. 2G,I) compared to controls (Fig. 2F,H). This increase was found primarily in the white matter and quantitative analysis showed it to be significant (Fig. 2s; $P<0.01$ ).
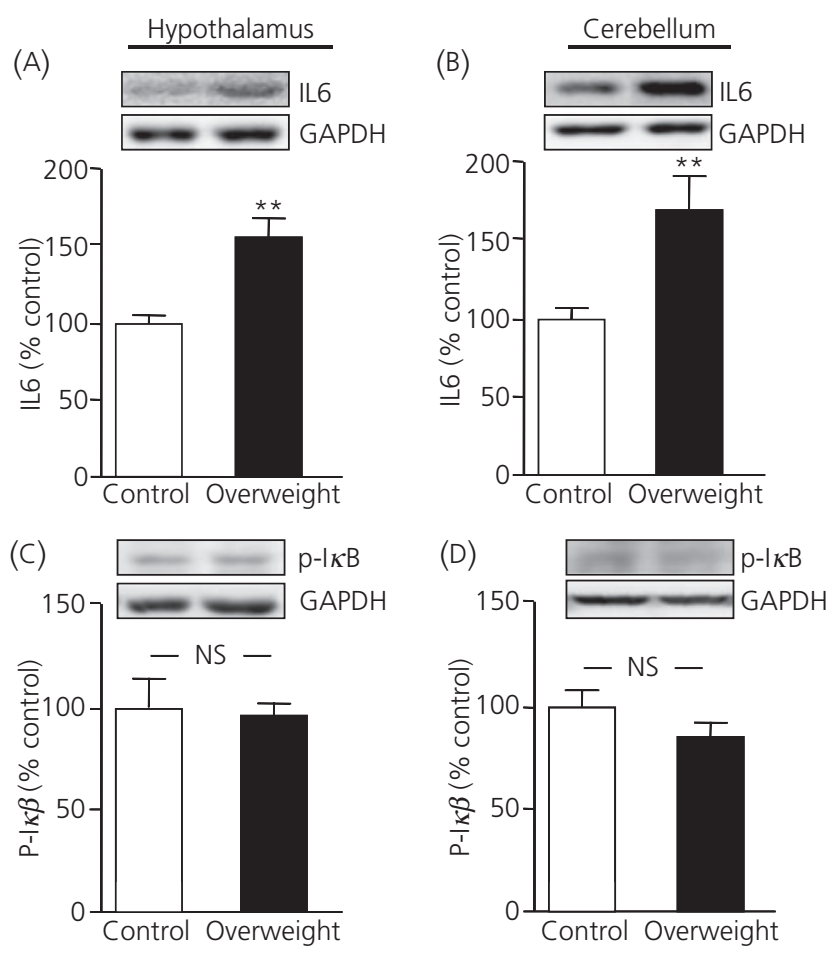

Fig. 1. Relative levels of interleukin (IL) $6(A, C)$ and phosphorylated $(p)-\mid \kappa B$ $(B, D)$ in the hypothalamus (left panel) and cerebellum (right panel) of control and overnourished rats as determined by western blotting ( $n=5-6$ per group). ${ }^{* *} \mathrm{P}<0.01$. GADPH, glyceraldehyde 3-phosphate dehydrogenase.

\section{Discussion}

Early overnutrition as a result of a change in litter size resulted in a significant increase in bodyweight in young adults, as reported previously (24). Although these rats were only approximately $15 \%$ heavier than their controls, they already had significantly higher serum leptin and IL6 levels, suggesting that this mild increase in bodyweight is already associated with at least some degree of systemic inflammation. IL6 levels were also increased in both the hypothalamus and cerebellum. As there was no change in the mRNA levels for this cytokine in either area, the increased protein levels could reflect an increase in IL6 uptake from the circulation.

Markers of inflammation reported to be increased in obese subjects and in response to a high-fat diet, such as increased F//80 levels or activation of the IKK $\beta / N F-\kappa B$ pathway, as well as increased IL6 or TNF $\alpha$ mRNA levels $(3-6,8,13)$, were not altered in the hypothalamus of neonatally overnourished rats. However, they did exhibit an increase in the number of activated microglia in specific hypothalamic nuclei. It is possible that the low degree of microglial activation in this experimental model is not detectable by methods such as western blotting. Similarly, changes in cytokine production in specific hypothalamic nuclei might not be detected in the assays of total hypothalamic mRNA employed in the present study. However, it is also possible that the hypothalamic inflammatory process, including microglial activation, in response to neonatal overnutrition and increased weight gain on a normal diet may 

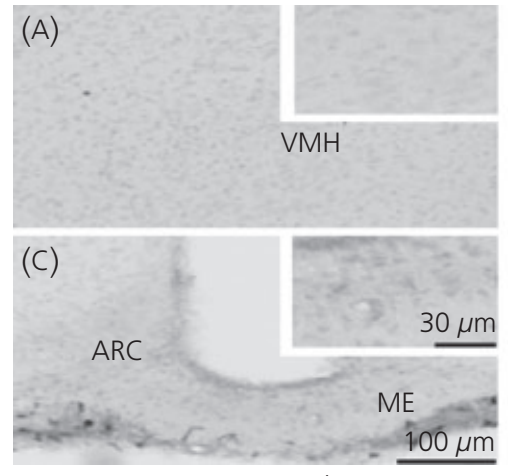

Control
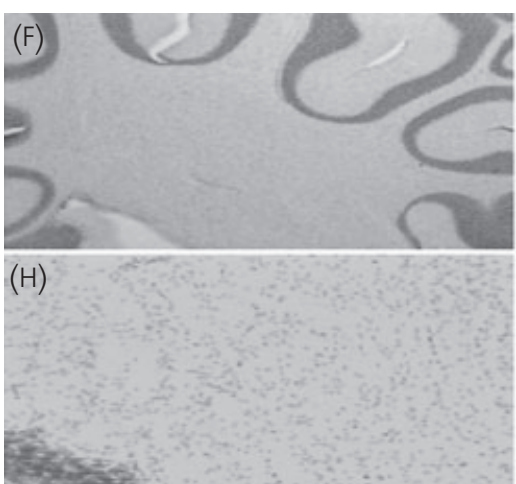

Control
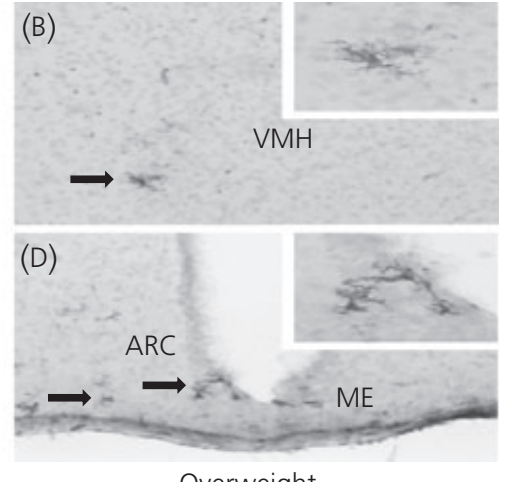

Overweight
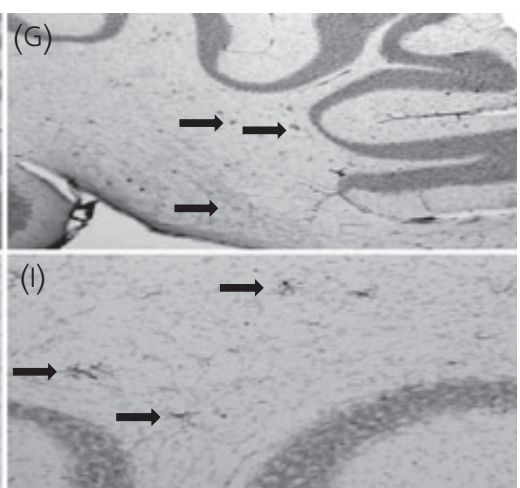

Overweight
(E)

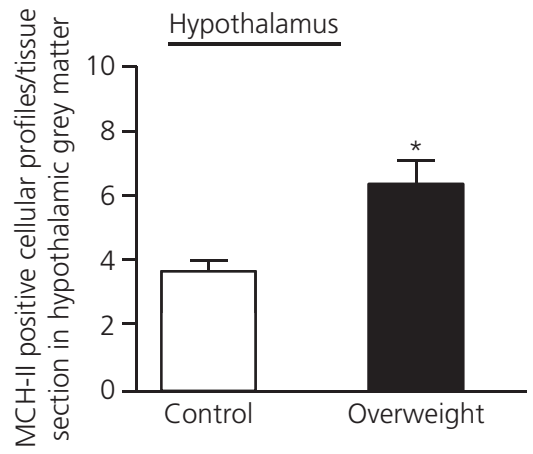

(J)

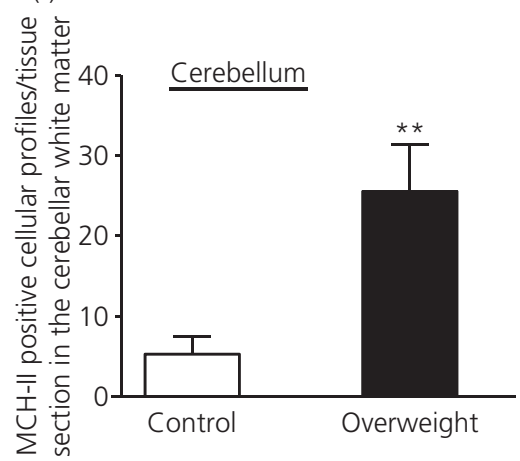

Fig. 2. Photomicrographs of major histocompatibility complex (MHC)-II immunopositive cells in the hypothalamus (A-D) and cerebellum (F-I) of control and overnourished male rats. There were significantly more MHC-II immunopositive cellular profiles per tissue section in both the hypothalamus (E) and cerebellum (J) of overnourished rats. VMH, ventromedial hypothalamus; ARC, arcuate nucleus; ME, median eminence $\left(n=5-6\right.$ per group). ${ }^{*} P<0.05,{ }^{* *} P<0.01$. Arrows indicate some of the activated microglia.

differ from that as a result of a high-fat diet, and thus may not result in activation of the IKK $\beta / \mathrm{NF}-\kappa \mathrm{B}$ pathway. Indeed, microglia can be activated by a number of factors that do not necessarily result in the same response $(17-19,25)$. Although IL6 activates microglia (25-27) systemic IL1 $\beta$ and TNF $\alpha$ injection, but not IL6, is reported to activate NF- $\kappa \mathrm{B}$, including in microglia (28). Moreover, IL6, which is considered to have both inflammatory and antiinflammatory effects, can have anti-obesity effects at the level of the hypothalamus (11).

The underlying cause of microglial activation in these neonatally overnourished animals remains to be elucidated. Although a longterm organisational effect of increased nutrition during development may be involved, being overweight during later life may also play an important role. It is possible that the increase in circulating leptin levels, in addition to the increase in IL6 levels, could be a triggering factor because this cytokine is also known to stimulate microglial activation and release of cytokines (14,17-19). In addition, it is likely that the state of activated microglia observed in the present study stems, at least partially, from early changes in bodyweight and chronic exposure to associated alterations in circulating levels of inflammatory adipokines, rather than from changes in adulthood. This may help to explain the differ- ences in patterns of hypothalamic inflammation compared to those observed with other forms of metabolic stress, such as a high-fat diet during adulthood. Inflammatory cytokines can influence neuropeptides involved in metabolic control (9-12) and microglial activation was increased in hypothalamic areas directly involved in this process. Thus, it might be speculated that the small increase in bodyweight throughout postnatal development,

Table 1. Mean \pm SEM Number of Major Histocompatibility Complex-II Positive Cells Per Tissue Section in Distinct Areas of the Hypothalamus of Adult Male Rats from Litters of 12 Pups (controls) and Rats Overnourished as a Result of Reduced Litter Size (Four Pups/Dam) from the Day of Birth.

\begin{tabular}{lccl}
\hline & Control & Overnourished & \\
\hline Optic chiasm & $1 \pm 0.3$ & $31 \pm 11$ & $\mathrm{P}<0.05$ \\
Paraventricular nucleus & $4 \pm 0.8$ & $5 \pm 0.9$ & $\mathrm{NS}$ \\
Ventromedial nucleus & $4 \pm 0.5$ & $8 \pm 0.9$ & $\mathrm{P}<0.005$ \\
Dorsomedial nucleus & $4 \pm 1.0$ & $8 \pm 2.0$ & $\mathrm{NS}$ \\
Arcuate nucleus & $3 \pm 0.4$ & $5 \pm 1.0$ & $\mathrm{NS}$ \\
Median eminence & $4 \pm 1.0$ & $14 \pm 3.0$ & $\mathrm{P}<0.02$ \\
& & & \\
\hline
\end{tabular}

NS, Not significant. 
which modifies circulating factors such as leptin, results in activation of hypothalamic microglia that in turn produce cytokines affecting the local neuroendocrine environment further exacerbating poor metabolic control and increased weight gain, as well as the response to further metabolic challenges. Indeed, animals with increased weight as a result of neonatal overnutrition are more prone to gain weight on a high-fat diet (24).

Activation of microglia was not specific to the hypothalamus because increased activation, as well as an increase in IL6 levels, was also found in the cerebellum. Moreover, in overnourished rats, more MHC-II positive cells could be seen throughout the white matter and in other brain areas such as the hippocampus (unpublished observation, S. Tapia-González, J. A. Chowen) suggesting a systemic source for central microglial activation. The cerebellum is one of the brain areas with the highest density of microglia (29) and is suggested to have an increased sensitivity to circulating inflammatory substances as a result of its microvascular structure (30) and, although not directly involved in the neuroendocrine control of metabolism, it plays an important role in the integration of the somatic-visceral control of food intake and motivation for food (31) and leptin receptor levels in the cerebellum are modified by high-fat diet (32). However, cerebellar microglial activation, as well as in other brain areas, could be involved in other pathophysiological responses to weight gain and changes in circulating factors.

In conclusion, neonatal overnutrition, which is associated with a small increase in adult bodyweight even on a normal diet, results in a significant increase in microglial activation in specific hypothalamic areas, as well as an increase in IL6 levels that may be a result of increased systemic uptake. Indeed, a systemic cause for this microglial activation is supported by the fact that this phenomenon was found in diverse areas of the brain. Whether microglial activation increases as the degree of obesity increases, and whether this activation in the hypothalamus is involved in perpetuating metabolic disturbances, deserves further investigation.

\section{Acknowledgements}

The authors would like to thank Paloma Carrero, Olga Pernía, Sandra Canelles and Francisca Díaz for the excellent technical support. Funding for this study was provided by grants from Fondo de Investigación Sanitaria (PI070182), Ministerio de Ciencia e Innovación (BFU2008-02950 C03-1, C03-3), CIBER de Fisiopatología de Obesidad y Nutrición (CIBEROBN) Instituto de Salud Carlos Il and Fundación de Endocrinologia y Nutrición.

Received 18 November 2010,

revised 5 January 2011,

accepted 16 January 2011

\section{References}

1 Frühbeck G. Overview of adipose tissue and its role in obesity and metabolic disorders. Methods Mol Biol 2008; 456: 1-22.

2 Karalis KP, Giannogonas P, Kodela E, Koutmani Y, Zoumakis M, Teli T. Mechanisms of obesity and related pathology: linking immune responses to metabolic stress. FEBS J 2009; 276: 5747-5754.
3 Posey KA, Clegg DJ, Printz RL, Byun J, Morton GJ, Vivekanandan-Giri A, Pennathur S, Baskin DG, Heinecke JW, Woods SC, Schwartz MW, Niswender KD. Hypothalamic proinflammatory lipid accumulation, inflammation, and insulin resistance in rats fed a high-diet. Am J Physiol Endocrinol Metab 2009; 296: E1003-E1012.

4 De Souza CT, Aroujo EP, Bordin S, Ashimine R, Zollner RL, Boschero AC, Saad MJ, Velloso LA. Consumption of a fat-rich diet activates a proinflammatory response and induces insulin resistance in the hypothalamus. Endocrinology 2005; 146: 4192-4199.

5 Milanski M, Degasperi G, Coope A, Morari J, Denis R, Cintra DE, Tsukumo $D M$, Anhe G, Amaral ME, Takahashi HK, Curi R, Oliveira HC, Carvalheira $J B$, Bordin S, Saad MJ, Velloso LA. Saturated fatty acids produce an inflammatory response predominantly through the activation of TLR4 signaling in hypothalamus: implications for the pathogenesis of obesity. J Neurosci 2009; 29: 359-370.

6 Oh-I S, Thaler JP, Ogimoto K, Wisse BE, Morton GJ, Schwartz MW. Central administration of interleukin-4 exacerbates hypothalamic inflammation and weight gain during high-fat feeding. Am J Physiol Endocrinol Metab 2010; 299: E47-E53.

7 Thaler JP, Choi SJ, Schwartz MW, Wisse BE. Hypothalamic inflammation and energy homeostasis: resolving the paradox. Front Neuroendocrinol 2010; 31: 79-84.

8 Grayson BE, Levasseur PR, Williams SM, Smith MS, Marks DL, Grove KL. Changes in melanocortin expression and inflammatory pathways in fetal offspring of nonhuman primates fed a high-fat diet. Endocrinology 2010; 151: 1622-1632.

9 DeBoer MD, Scarlett JM, Levasseur PR, Grant WF, Marks DL. Administration of IL-1beta to the 4th ventricle causes anorexia that is blocked by agouti-related peptide and that coincides with activation of tyrosinehydroxylase neurons in the nucleus of the solitary tract. Peptides 2009; 30: 210-218.

10 Scarlett JM, Jobst EE, Enriori PJ, Bowe DD, Batra AK, Grant WF, Cowley MA, Marks DL. Regulation of central melanocortin signaling by interleukin-1beta. Endocrinology 2007; 148: 4217-4225.

11 Wallenius V, Wallenius K, Ahrén B, Rudling M, Carlsten H, Dickson SL, Ohlsson C, Jansson J0. Interleukin-6-deficient mice develop matureonset obesity. Nat Med 2002; 8: 757-759.

12 Amaral ME, Barbuio R, Milanski M, Romanatto T, Barbosa HC, Nadruz W, Bertolo MB, Boschero AC, Saad MJ, Franchini KG, Velloso LA. Tumor necrosis factor-alpha activates signal transduction in hypothalamus and modulates the expression of pro-inflammatory proteins and orexigenic/anorexigenic neurotransmitters. J Neurochem 2006; 98: 203-212.

13 Zhang X, Zhang G, Zhang H, Karin M, Bai H, Cai D. Hypothalamic IKKbeta/NF-kappaB and ER stress link overnutrition to energy imbalance and obesity. Cell 2008; 135: 61-73.

14 Ransohoff RM, Perry VH. Microglial physiology: unique stimuli, specialized responses. Annu Rev Immunol 2009; 27: 119-145.

15 Nakajima K, Kohsaka S. Microglia: activation and their significance in the central nervous system. J Biochem 2001; 130: 169-175.

16 Yong VW, Marks S. The interplay between the immune and central nervous systems in neuronal injury. Neurology 2010; 74: S9-S16.

17 Pinteaux E, Inoue W, Schmidt L, Molina-Holgado F, Rothwell NJ, Luheshi GN. Leptin induces interleukin-1beta release from rat microglial cells through a caspase 1 independent mechanism. J Neurochem 2007; 102: 826-833.

18 Tang CH, Lu DY, Yang RS, Tsai HY, Kao MC, Fu WM, Chen YF. Leptininduced IL-6 production is mediated by leptin receptor, insulin receptor substrate-1, phosphatidylinositol 3-kinase, Akt, NF-kappaB, and p300 pathway in microglia. J Immunol 2007; 179: 1292-1302.

19 Lafrance V, Inoue W, Kan B, Luheshi GN. Leptin modulates cell morphology and cytokine release in microglia. Brain Behav Immun 2010; 24: 358-365. 
20 Gomez-Nicola D, Valle-Argos B, Nieto-Sampedro M. Blockade of IL-15 activity inhibits microglial activation through the NFkappaB, p38, and ERK1/2 pathways, reducing cytokine and chemokine release. Glia 2010; 58: $264-276$.

21 Tapia-Gonzalez S, Carrero P, Pernia O, Garcia-Segura LM, Diz-Chaves Y. Selective oestrogen receptor (ER) modulators reduce microglia reactivity in vivo after peripheral inflammation: potential role of microglial ERs. J Endocrinol 2008; 198: 219-230.

22 Lechuga-Sancho AM, Arroba Al, Frago LM, Garcia-Cáceres C, de Célix $A D$, Argente J, Chowen JA. Reduction in the number of astrocytes and their projections is associated with increased synaptic protein density in the hypothalamus of poorly controlled diabetic rats. Endocrinology 2006; 147: 5314-5324.

23 Granado M, Garcia-Cáceres C, Frago LM, Argente J, Chowen JA. The positive effects of growth hormone-releasing peptide- 6 on weight gain and fat mass accrual depend on the insulin/glucose status. Endocrinology 2010; 151: 2008-2018.

24 Glavas MM, Kirigiti MA, Xiao XO, Enriori PJ, Fisher SK, Evans AE, Grayson $B E$, Cowley MA, Smith MS, Grove KL. Early overnutrition results in earlyonset arcuate leptin resistance and increased sensitivity to high-fat diet. Endocrinology 2010; 151: 1598-1610.

25 Krady JK, Lin HW, Liberto CM, Basu A, Kremlev SG, Levison SW. Ciliary neurotrophic factor and interleukin-6 differentially activate microglia. J Neurosci Res 2008; 86: 1538-1547.
26 Latrémolière A, Mauborgne A, Masson J, Bourgoin S, Kayser V, Hamon M, Pohl M. Differential implication of proinflammatory cytokine interleukin-6 in the development of cephalic versus extracephalic neuropathic pain in rats. $J$ Neurosci 2008; 28: 8489-8501.

27 Lee KM, Jeon SM, Cho HJ. Interleukin-6 induces microglial CX3CR1 expression in the spinal cord after peripheral nerve injury through the activation of p38 MAPK. Eur J Pain 2010; 14: 682.

28 Laflamme $N$, Rivest $\mathrm{S}$. Effects of systemic immunogenic insults and circulating proinflammatory cytokines on the transcription of the inhibitory factor kappaB alpha within specific cellular populations of the rat brain. J Neurochem 1999; 73: 309-321.

29 Savchenko VL, McKanna JA, Nikonenko IR, Skibo GG. Microglia and astrocytes in the adult rat brain: comparative immunocytochemical analysis demonstrates the efficacy of lipocortin 1 immunoreactivity. Neuroscience 2000; 96: 195-203.

30 Silwedel C, Förster C. Differential susceptibility of cerebral and cerebellar murine brain microvascular endothelial cells to loss of barrier properties in response to inflammatory stimuli. J Neuroimmunol 2006; 17: $37-45$.

31 Zhu JN, Wang JJ. The cerebellum in feeding control: possible function and mechanism. Cell Mol Neurobiol 2008; 28: 469-478.

32 Koros C, Boukouvalas G, Gerozissis K, Kitraki E. Fat diet affects leptin receptor levels in the rat cerebellum. Nutrition 2009; 25: 85-87. 